\section{A new journal, a new start}

\section{Theofilou Paraskevi1,2}

1Sotiria Hospital for Thoracic Diseases; 2Department of Psychology, Panteion University, Athens, Greece

Health psychology has been the most rapidly growing field of psychology of the past 15 years. It is an exciting area of study devoted to understanding the psychological influences on how people stay healthy, why they become ill and how they respond when they do. Specifically, this field is concerned with understanding human behavior in the context of health and illness. As such, it covers a wide area of interest including how individuals cope with illness and chronic disease, the psychological influences on the development of disease states, understanding and improving personal adjustment to healthcare settings, patient - practitioner communication, adherence to treatment, determinants of healthrelated behaviors (diet, exercise, etc.), and understanding how individuals make sense of and react to health screening, symptoms and illness. Health psychologists both study such issues and also promote interventions to help people stay well or recover from illness. For example, a health psychology researcher might be interested in why people continue to smoke even though they know that smoking increases their risk of cancer and heart disease.
Information about why people smoke helps the researcher both understand this poor health habit and design interventions to help people stop. Health psychology emerged in the 1970s, when forward-thinking scientists advanced the notion that health reflects the complex interplay of physiological, psychological and social factors. The impetus for the development of health psychology stemmed from the fact that many of the areas of research and practice had not been directly addressed by medicine. Interest in this field has been further stimulated by the usefulness of psychological models in explaining patient behavior and developing effective interventions in problematic areas in the health field. There is increased recognition of the need for health services to pay more attention to the psychological aspects of medical problems and to improve healthcare interactions. Increasingly, health professionals are dealing with chronic illness, ageing and the problems of living with disability, and health psychology is an important component of their work. Health psychologists generally hold a holistic perspective on individual wellbeing. While the primary focus is on physical rather than mental health, in reality it is acknowledged that these are two sides of the same coin. When a person has a physical illness they can experience anxiety or depression. When a person has a mental illness their behavior or treatment may well have a negative impact on their physical health leading to deterioration in their physical wellbeing. Feeling well
Correspondence: Theofilou Paraskevi, Sotiria Hospital for Thoracic Diseases, Athens; Panteion University, Department of Psychology, Athens, Greece. E-mail: theofi@otenet.gr

Conflict of interest: the authors report no conflicts of interest.

Received for publication: 6 October 2012. Accepted for publication: 6 October 2012.

This work is licensed under a Creative Commons Attribution NonCommercial 3.0 License (CC BYNC 3.0).

CCopyright T. Paraskevi, 2013

Licensee PAGEPress, Italy

Health Psychology Research 2013; 1:e1 doi:10.4081/hpr.2013.e1

involves mind, body and spirit. At a practical level, the health psychologist is concerned with the behavior and experience of the individual, the interface of the individual with the healthcare system, and with society as a whole. This new journal, Health Psychology Research, creates a space where all contributions in these broad areas will be welcomed in order to develop knowledge and promote the health and wellbeing of both the individual and communities.

Thank you for your support. We look forward to receiving your contribution! 